\title{
Investigating the Structure of Self-Assembled Monolayers Related to Biological Cell Membranes
}

\author{
Ahlam R. M. Alharbi ${ }^{1}$, Jakob Andersson ${ }^{1,3}$, Ingo Köper ${ }^{1}$, Gunther G. Andersson ${ }^{1,2^{*}}$ \\ 1 Flinders Institute for Nanoscale Science and Technology, College of Science and \\ Engineering, Flinders University, Adelaide SA 5001, Australia \\ 2 Flinders Microscopy and Microanalysis, College of Science and Engineering, Flinders \\ University, Adelaide, SA 5001, Australia \\ 3 Austrian Institute of Technology, Biosensor Technologies, 1210 Vienna, Austria
}

*Corresponding author: Email gunther.andersson@flinders.edu.au

\section{Supplementary Material}

Number of pages: 2

Number of figures: 1

Number of tables: 1 


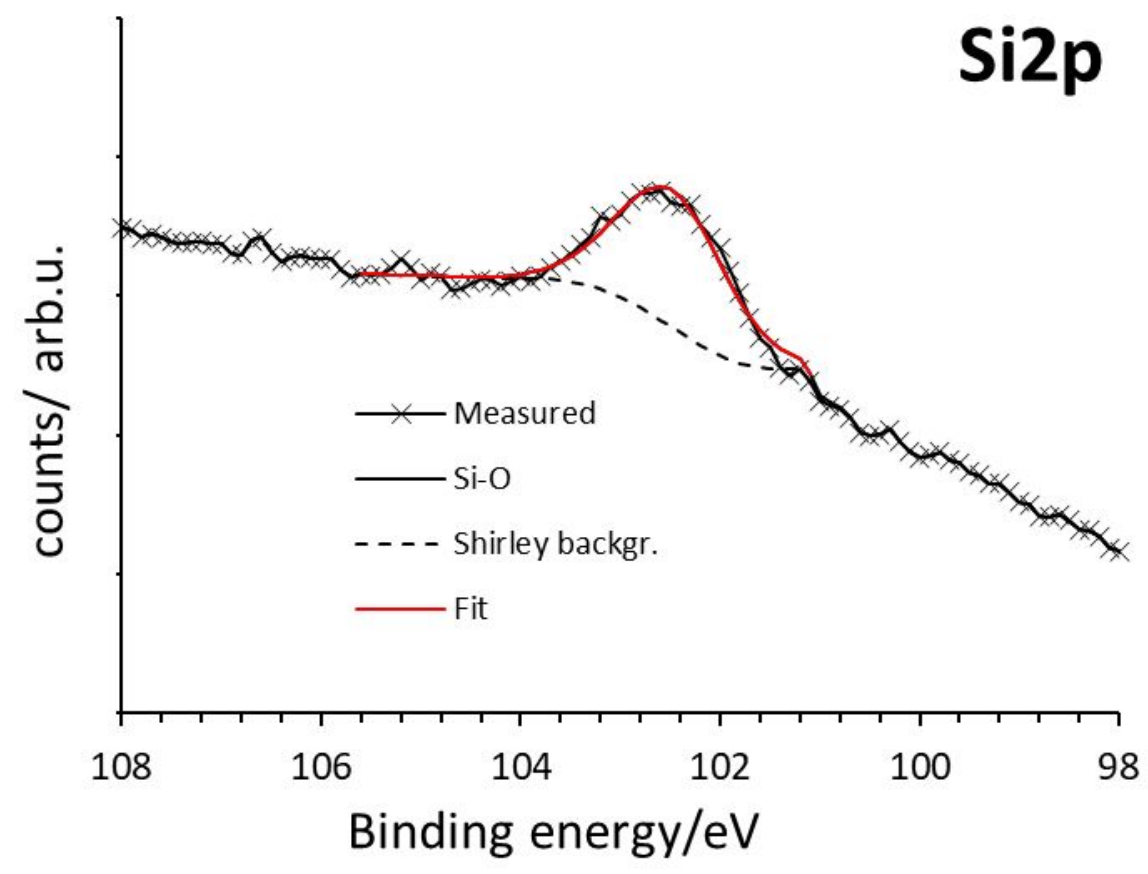

Figure S1: XP high resolution spectrum of the Si2p region.

Table S1: Thickness of SAMs of DPhyTL and of SAMs of 0.16mg/ml of DPhyTL with $0.04 \mathrm{mg} / \mathrm{ml}$ of ME for five different immersing times as determined with NICISS.

\begin{tabular}{|c|c|c|c|c|c|}
\hline Immersing time (mins) & $\mathbf{5}$ & $\mathbf{1 5}$ & $\mathbf{3 0}$ & $\mathbf{6 0}$ & $\mathbf{1 4 4 0}$ \\
\hline DPhyTL (nm) & $2.3 \pm 0.4$ & $2.6 \pm 0.4$ & $2.7 \pm 0.4$ & $3.2 \pm 0.4$ & $3.9 \pm 0.4$ \\
\hline DPhyTL with ME (nm & $3 \pm 0.4$ & $2.9 \pm 0.4$ & $3.4 \pm 0.4$ & $1.6 \pm 0.4$ & $1 \pm 0.4$ \\
\hline
\end{tabular}

